\title{
ESTUDO DA PERCEPÇÃO DE ALUNOS DE ENSINO FUNDAMENTAL E MÉDIO REFERENTE A RESÍDUOS SÓLIDOS, ANTES E APÓS SENSIBILIZAÇÃO
}

\author{
Everton Mario de Oliveira ${ }^{1}$ \\ Fátima de Jesus Bassetti ${ }^{2}$
}

\begin{abstract}
RESUMO
A gestão dos resíduos sólidos tem se tornado um grande problema nas últimas décadas. O aumento do consumo de produtos industrializados pelas pessoas tem proporcionado uma grande geração de resíduos sólidos, que está ocorrendo sem que essas pessoas se preocupem com os impactos ambientais decorrentes e, consequentemente, com as necessidades das gerações futuras. A sensibilização, que é uma das ferramentas da educação ambiental, tem sido usada para promover a minimização e o descarte correto de resíduos sólidos. Assim, este estudo investigou as percepções referentes aos resíduos sólidos, por alunos de um colégio público no município de Mandirituba/PR, antes e após sensibilização por palestra interativa. Para tal, foi realizado um diagnóstico do conhecimento dos alunos em relação a resíduos sólidos através de um questionário elaborado. Após a análise dessa ferramenta foi desenvolvida e realizada uma palestra interativa sobre resíduos sólidos. Durante a realização da palestra, percebeu-se que os alunos demonstraram interesse pelo tema, interagindo com o palestrante. Após a palestra percebeu-se uma melhora na percepção dos alunos com relação a diversas questões relacionadas a resíduos sólidos, tais como: coleta seletiva e técnicas de redução de resíduos sólidos; separação dos resíduos; e minimização da geração de resíduos sólidos, tendo a exposição de opiniões e apresentação de ideias pelos participantes.
\end{abstract}

PALAVRAS-CHAVE: Percepção ambiental. Sensibilização. Palestra.

\section{STUDENTS PERCEPTION STUDY PRIMARY EDUCATION AND RELATED MEDIUM SOLID WASTE BEFORE AND AFTER RAISING}

\begin{abstract}
The solid waste management has become a major problem in recent decades. Increased consumption of processed products by people has provided a great generation of solid waste that is occurring without these people worry about the environmental impacts and, consequently, with the needs of future generations. This awareness, which is one of the tools of environmental education, has been used to promote minimization and proper disposal of solid waste. Thus, this study investigated the perceptions related to solid waste, by students of a public school in the city of

\footnotetext{
${ }^{1}$ Graduado em Geografia, Mestre em Ciência e Tecnologia Ambiental pela Universidade Tecnológica Federal do Paraná (UTFPR), Programa de Pós Graduação em Ciência e Tecnologia Ambiental/ PPGCTA/ CEP - 81280-340 - Curitiba - Paraná - Brasil. E-mail: everton.utp@hotmail.com

${ }^{2}$ Graduada em Engenheira Química, Doutora em Engenharia Química pela Universidade Estadual de Campinas. Professora da Universidade Tecnológica Federal do Paraná (UTFPR), Programa de Pós Graduação em Ciência e Tecnologia Ambiental/ PPGCTA/ CEP - 81280-340 - Curitiba - Paraná Brasil. E-mail: bassetti@utfpr.edu.br
} 
Mandirituba / PR before and after sensitization by interactive lecture. For this, a diagnosis of students' knowledge in relation to solid waste was conducted through a questionnaire. After analyzing this tool was developed and implemented an interactive lecture on solid waste. During the completion of the lecture, it was noticed that the students showed interest in the subject, interacting with the speaker. After the lecture we felt an improvement in the perception of the students regarding various issues related to solid waste, such as selective techniques and collecting solid waste reduction; separation of waste; and minimizing the generation of solid waste, and the exposure of opinions and ideas presented by the participants.

KEYWORDS: Environmental perception. Awareness. Lecture.

\title{
ESTUDIANTES PERCEPCIÓN DE EDUCACIÓN PRIMARIA DE ESTUDIO Y AFINES MEDIO DE RESIDUOS SÓLIDOS ANTES Y DESPUÉS QUE LEVANTA
}

\begin{abstract}
RESUMEN
La gestión de los residuos sólidos se ha convertido en un problema importante en las últimas décadas. El aumento del consumo de productos manufacturados por el pueblo ha proporcionado una gran generación de residuos sólidos, que está teniendo lugar sin estas personas se preocupan acerca de los impactos ambientales y por lo tanto a las necesidades de las generaciones futuras. Conciencia, que es una de las herramientas de educación ambiental, se ha utilizado para promover la minimización y eliminación adecuada de los residuos sólidos. Este estudio investigó las percepciones relacionadas con los residuos sólidos, para los estudiantes de una escuela pública en el municipio de Mandirituba / PR antes y después de sensibilización en conferencia interactiva. Para ello, se realizó un diagnóstico de conocimientos de los alumnos en relación con los residuos sólidos a través de un cuestionario. Después de analizar esta herramienta fue desarrollado y realizado una conferencia interactiva sobre residuos sólidos. Durante el transcurso de la conferencia, se observó que los estudiantes mostraron interés en el tema, que interactúa con el altavoz. Después de la conferencia se observó una mejora en la percepción de los estudiantes sobre diversos temas relacionados con los residuos sólidos, tales como: la recogida selectiva y técnicas de reducción de los residuos sólidos; la separación de los residuos; y minimizar la generación de residuos sólidos, con la exposición de puntos de vista y presentación de ideas de los participantes.
\end{abstract}

PALABRAS CLAVE: La conciencia ambiental. Conciencia. Conferencia.

\section{INTRODUÇÃO}

Os resíduos sólidos são produzidos desde o início da civilização. Porém, durante os primeiros períodos foram discretamente eliminados em grandes espaços abertos da terra, pois a densidade da população era baixa e a produção de resíduos era praticamente composta de orgânicos, facilmente biodegradáveis. No entanto, hoje, uma das consequências da rápida urbanização é o grande aumento da quantidade de resíduos sólidos, não só orgânicos, facilmente biodegradáveis, mas também uma grande quantidade de resíduos secos oriundos de embalagens, dentre outros.

A produção de resíduos sólidos tem alcançado índices preocupantes nos últimos anos, como consequência da rápida urbanização. No Brasil o índice de 
geração de resíduos sólidos alcança uma média de 1,03 kg por habitante dia (ABRELPE, 2013) e em algumas regiões de países mais desenvolvidos como os Estados Unidos, um cidadão pode gerar mais de $3 \mathrm{~kg}$ de resíduos diariamente (ONOFRE, 2011).

Uma das prováveis causas do elevado índice de geração de resíduos é o acesso facilitado aos produtos industrializados. Há algumas décadas, as pessoas não tinham muitas opções de compras, a diversidade de produtos industrializados era bem menor, e o número de supermercados, lojas, shoppings centers, entre outros, era bastante reduzido. Ainda, os consumidores também adquiriam produtos in natura, sem a necessidade de embalagens, o que contribuía para a baixa geração de resíduos sólidos secos. Atualmente, as atividades comerciais vêm passando por um período de grande expansão, o que aumenta o número de estabelecimentos e, consequentemente, as opções de compra.

O processo de industrialização, juntamente com a crescente concentração populacional em áreas urbanas sem infraestrutura, e o incentivo ao consumismo, são os principais responsáveis pelo agravamento dos problemas sociais, ambientais e de saúde pública causados por resíduos sólidos (MORAES; SIQUEIRA, 2009). Os atuais padrões de consumo são impulsionados principalmente pela mídia, que por meio da obsolescência planejada e da obsolescência percebida, torna os produtos obsoletos, induzindo o consumidor a comprar um produto novo e "mais moderno" (RODRIGUES, 2010). Ainda, o estado da economia tende a influenciar a geração de resíduos, uma vez que, normalmente, uma maior prosperidade econômica resulta em uma geração maior de resíduos sólidos, que é uma característica comum em países desenvolvidos e em desenvolvimento (CHATTOPADHYAY; DUTTA; RAY, 2009).

Outra provável causa contribuinte para o alto índice de geração de resíduos sólidos é a falta de conscientização da população e dos órgãos públicos sobre a questão da redução, reutilização e reciclagem, pois a gestão de resíduos sólidos urbanos, ainda é uma área muito negligenciada, principalmente em países em desenvolvimento (BATOOL; NAWAZ, 2009). Porém, nos últimos anos a maioria desses países começou a melhorar seus sistemas de gestão de resíduos sólidos (MOGHADAM; MOKHTARANI; MOKHTARANI, 2009). Segundo o Instituto Brasileiro de Geografia e Estatística (IBGE, 2011), apenas cerca de 33\% do total de 
municípios brasileiros realizam uma destinação adequada dos resíduos sólidos produzidos, conforme estabelecida pela Política Nacional de Resíduos Sólidos. Ainda, cerca de $50,8 \%$ dos municípios utilizam vazadouros a céu aberto (lixões) como destino final dos resíduos sólidos. Uma das prováveis causas para que os municípios não realizem a gestão de seus resíduos sólidos pode ser a falta de orientação quanto à formulação de um plano de gerenciamento de resíduos sólidos (MATTEI; ESCOSTEGUY, 2007).

De acordo com a Política Nacional de Resíduos Sólidos - Lei 12305/2010 (BRASIL, 2010, p. 2), gestão integrada de resíduos sólidos é o "conjunto de ações voltadas para a busca de soluções para os resíduos sólidos, de forma a considerar as dimensões política, econômica, ambiental, cultural e social, sob a premissa do desenvolvimento sustentável”. Segundo Pedrozo e Ceruti (2009), a Política Nacional de Resíduos Sólidos, quando entrasse em vigor, seria um instrumento de fundamental importância para a implementação da gestão dos resíduos sólidos urbanos nos municípios brasileiros, pois a coleta, transporte, tratamento e disposição de resíduos sólidos, em particular os gerados em médios e grandes centros urbanos, tornar-se-iam um problema relativamente difícil de resolver (ZHANG; KEAT; GERSBERG, 2010), e cada município teria o dever de propor o seu próprio plano de gerenciamento de resíduos sólidos.

A gestão de resíduos sólidos não se restringe apenas à coleta, transporte, destinação e disposição final, pois essas etapas ocorrem após a geração dos resíduos, sendo que a gestão também aborda etapas anteriores à geração. $\mathrm{A}$ Política Nacional de Resíduos Sólidos tem como um de seus objetivos, promover a minimização dos resíduos sólidos, adotando a seguinte ordem de prioridade: não geração; redução; reutilização; reciclagem; tratamento dos resíduos perigosos; e disposição final ambientalmente adequada dos rejeitos (BRASIL, 2010).

Uma das formas dos órgãos públicos reduzirem a totalidade dos resíduos sólidos que serão gerenciados é aplicar e apoiar projetos de educação e sensibilização ambiental na comunidade, e incentivar práticas ambientalmente corretas de gestão de resíduos, como a minimização e a valorização. "A educação ambiental é uma estratégia muito utilizada para minimizar os impactos ambientais" (DAMINELLI; SILVA, 2009, p. 56), dentre eles os problemas causados pelos resíduos sólidos, sendo os resíduos sólidos, um tema tão complexo, que é um dos 
mais presentes nas ações ambientalistas, bem como nas ações de educação ambiental (TOZONI-REIS, 2008).

As ações de educação ambiental devem ser críticas e inovadoras, além de ter um enfoque humanista, holístico, democrático, participativo e sustentável. $\mathrm{Na}$ implementação de práticas de educação ambiental, o desenvolvimento de projetos é uma das mais ricas possibilidades (TOZONI-REIS, 2008).

Não existe um método pré-estabelecido para a elaboração de projetos de educação ambiental, pois cada ação deve ser desenvolvida com base nas carências dos indivíduos, que devem ser apontadas em um estudo sobre o diagnóstico da percepção ambiental do público alvo. Porém, um programa de educação ambiental eficiente deve promover, simultaneamente, o desenvolvimento de conhecimento, de atividades e de habilidades necessárias à preservação e melhoria da qualidade ambiental (SOARES; SALGUEIRO; GAZINEU, 2007), e assim, sensibilizar as populações com as implicações dos reflexos negativos dos resíduos sólidos para o meio ambiente, e desenvolver nos indivíduos a consciência de suas responsabilidades perante os problemas ambientais.

Uma das alternativas para desenvolver um projeto de educação ambiental é trabalhar um conjunto diversificado de técnicas que possibilitem aos alunos intervir na sua própria realidade (CRISOSTIMO, 2011). As principais atividades em projetos de educação ambiental são de caráter lúdico, como palestras, gincanas, brincadeiras e jogos, pois as atividades lúdicas promovem o prazer em aprender (BASTOS; MACEDO; MOREIRA, 2005). Segundo Brasília (2001), a palestra, como técnica de sensibilização ambiental, em particular, pode tratar temas que estão tanto presentes no cotidiano dos sujeitos quanto em cenários globais.

\section{OBJETIVO}

O objetivo desse trabalho foi avaliar a percepção ambiental de alunos que estudam em um colégio público e sensibilizá-los quanto às técnicas de minimização de resíduos sólidos, por meio de palestra interativa. 


\section{MATERIAL E MÉTODOS}

A pesquisa desenvolveu-se em um colégio estadual localizado na comunidade de Areia Branca dos Assis, município de Mandirituba, que pertence a Região Metropolitana de Curitiba, porção leste-sudeste do Estado do Paraná, às margens da Rodovia Federal BR 116 sentido sul (Curitiba - Rio Negro). Mandirituba possui uma população de 22220 habitantes (IBGE, 2010) e uma área territorial de aproximadamente $381 \mathrm{~km}^{2}$ (IPARDES, 2012). A Figura 1 representa a localização do município de Mandirituba.

Figura 1: Localização do município de Mandirituba.

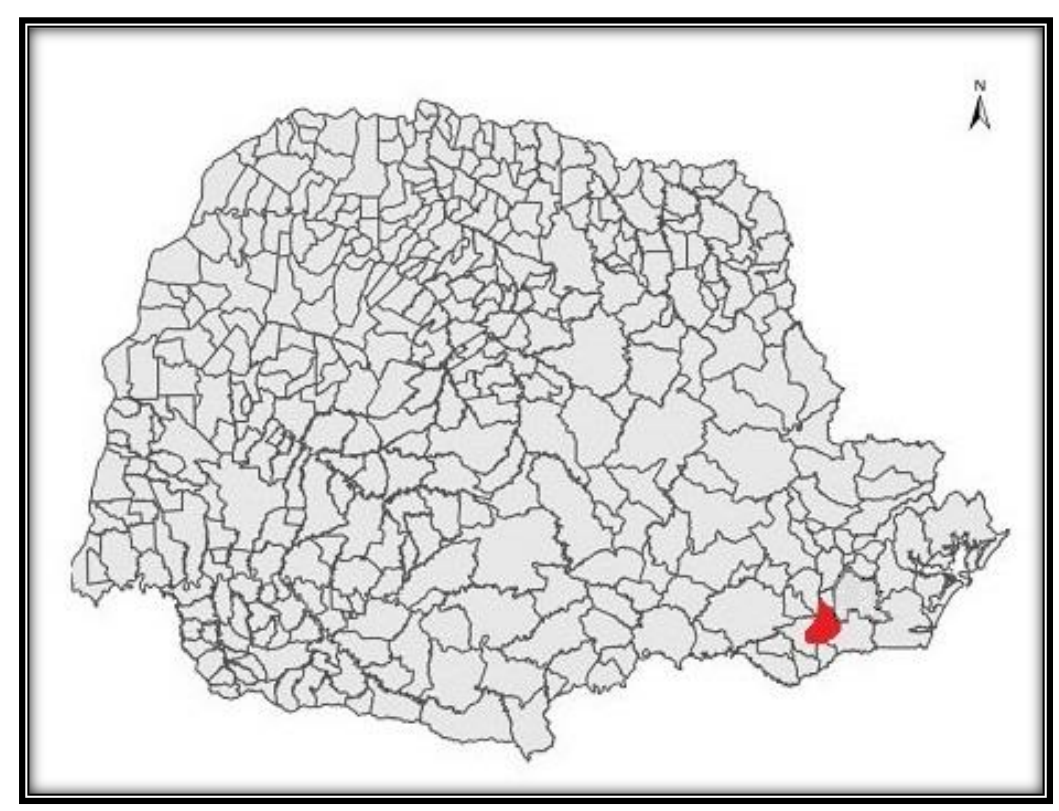

Fonte: Adaptado de Prefeitura Municipal de São José dos Pinhais (2014).

O colégio oferece educação do $6^{\circ}$ ao $9^{\circ}$ ano do Ensino Fundamental e para todo Ensino Médio, contando com cerca de 950 alunos distribuídos em 30 turmas.

Foi usado como primeiro passo no desenvolvimento de uma sensibilização ambiental, o diagnóstico da percepção ambiental do público alvo3 ${ }^{3}$ Esta etapa foi realizada com o auxílio de um questionário desenvolvido e aplicado aos alunos com perguntas abertas e fechadas sobre os resíduos sólidos e os impactos ambientais causados por eles.

Foi identificada no diagnóstico da percepção ambiental, uma defasagem do conhecimento dos alunos em relação aos resíduos sólidos. Sendo assim, 
evidenciou-se a necessidade da inclusão de atividades de sensibilização ambiental no cotidiano dos alunos.

Num primeiro momento, foi feita a sensibilização através de palestras desenvolvidas em relação aos resíduos sólidos. A palestra foi realizada nos três turnos (manhã, tarde e noite), abordando temas referentes à quantidade de resíduos sólidos gerados; aos impactos ambientais causados pela disposição inadequada dos resíduos; e as formas de minimização dos impactos ambientais e da quantidade dos resíduos sólidos gerados.

Nos turnos da manhã e tarde, os alunos foram deslocados, com a ajuda dos professores, até o teatro municipal da comunidade de Areia Branca dos Assis, que foi cedido para a realização da palestra. Durante a realização da palestra, os alunos foram convidados a interagir com o palestrante, expondo seus conhecimentos e suas dúvidas.

Iniciou-se a palestra expondo imagens dos impactos ambientais causados pelos resíduos sólidos em ambientes naturais. Após, explicou-se a diferença entre resíduo sólido e "lixo", informando sobre a geração per capita brasileira de resíduos sólidos. Depois, foram expostos o aterro sanitário e o "lixão a céu aberto" como sendo os principais locais de disposição final dos resíduos. Em seguida apresentouse, em ordem de prioridade, as técnicas de minimização de resíduos sólidos estabelecidas pela Política Nacional de Resíduos Sólidos, sendo a não geração, redução, reutilização, reciclagem, destinação e disposição final adequada (BRASIL, 2010). Finalizando a palestra, foi exposto como deve ser realizada a seleção dos resíduos para facilitar a reciclagem, e os meios de utilização dos resíduos orgânicos.

Como instrumento de avaliação da atividade de sensibilização desenvolvida, optou-se pela utilização de um novo questionário, também com perguntas abertas e fechadas, o qual foi aplicado após a realização da palestra a 200 alunos, com o objetivo de identificar as percepções ambientais dos alunos.

A análise dos dados obtidos foi feita de forma quantitativa, sendo alguns resultados expressos graficamente e algumas citações transcritas em quadros. 


\section{RESULTADOS E DISCUSSÃO}

\subsection{DIAGNÓSTICO DA PERCEPÇÃO AMBIENTAL}

A busca das identidades e percepções dos sujeitos envolvidos em atividades de sensibilização ambiental deve ocorrer com base em instrumentos de coleta de dados, como conversas, entrevistas ou questionários (SPAZZIANI; SILVA, 2009). Logo, como forma de avaliar possíveis diferenças, olhares e dimensões da percepção ambiental, antes das atividades de sensibilização (CAMPOS et al., 2012), a ferramenta utilizada para o diagnóstico foi o questionário aplicado aos alunos. As análises das questões abordadas no questionário estão apresentadas em forma de tópicos na sequência.

\section{Você sabe o que é "lixo"?}

Os alunos poderiam escolher entre duas alternativas para suas respostas, "sabe" e "não sabe". Também foi solicitado aos alunos explicarem sua resposta, redigindo um pequeno parágrafo sobre sua concepção quanto ao tema. Com essa descrição que os alunos elaboraram, foi possível identificar e quantificar os alunos capazes de compreender e explicar o que são resíduos sólidos. Do total de respostas, apenas $38 \%$ têm conhecimento sobre o significado do conceito resíduo sólido. Os demais, $62 \%$ dos alunos, não souberam definir resíduos sólidos.

\section{Qual a frequência da separação dos resíduos sólidos produzidos em sua residência?}

Analisando as respostas, observou-se que $46,6 \%$ dos alunos relataram que nem sempre realizam a separação; outros $12,6 \%$ nunca fazem a separação; e somente $41,8 \%$ responderam que sempre separam seus resíduos.

\section{Você sabe a diferença entre resíduos recicláveis e orgânicos?}

Os alunos foram solicitados a descrever em um pequeno parágrafo explicando sua resposta. Assim foi possível identificar os alunos que realmente possuem esse conhecimento. Com a análise das respostas, identificou-se que a maioria dos alunos, $53 \%$ não soube explicar suas respostas, e apenas $47 \%$ realmente souberam explicar a diferença entre resíduos recicláveis e resíduos orgânicos.

Em qual local você recebe mais informações sobre resíduos sólidos e problemas causados por eles?

Percebeu-se que, embora apresentem pouco conhecimento sobre o tema, a escola é o local onde os alunos obtêm mais informações sobre resíduos sólidos e os 
problemas ambientais, sociais e econômicos causados pelo seu descarte inadequado. A escola foi apontada por $70,1 \%$ dos alunos, seguida pelos programas de televisão $(14,2 \%)$, jornais $(3,8 \%)$, internet $(2,4 \%)$, revistas $(0,7 \%)$, entre outros (7\%).

Através da análise das questões anteriores, percebeu-se que há falta de conhecimento dos alunos em relação aos resíduos sólidos, o que comprova carências no processo ensino-aprendizagem. Por se tratar de um tema novo, a Política Nacional de Resíduos Sólidos ainda é desconhecida no ambiente escolar, sendo um assunto recente entre os professores (JANKE et al., 2012). No Projeto Político Pedagógico do colégio, documento que rege toda a sua gestão e deve ser seguido pelos professores, nenhum tema que abordasse educação ambiental ou resíduos sólidos foi encontrado, e essa é uma falha bastante importante, pois a problemática dos resíduos sólidos vem sendo discutida por vários veículos de informação há muitos anos. Isso sugere que a temática resíduos sólidos, não está sendo devidamente abordada pelos professores com os alunos, e esse pode ser o motivo pelo qual os alunos apresentaram pouco conhecimento sobre o assunto. De acordo com Wang et al. (2013), é preciso preparar os alunos para conseguir uma mudança nos hábitos da sociedade.

Segundo Layrargues (2006), a educação ambiental deve ser implementada primeiramente nas escolas. Isso porque é nelas que os menores indivíduos de uma sociedade passam grande parte de seu tempo. Além disso, o conhecimento e o pensamento crítico estão sendo formados nesse ambiente. Após o desenvolvimento de trabalhos que abordem temas ambientais, como os resíduos sólidos, os alunos têm tendência a tomar consciência dos problemas e mudar suas atitudes em relação ao tema que foi trabalhado (SANTOS, 2007).

Desta forma, sabendo que os alunos não têm conhecimento suficiente sobre resíduos sólidos, e que a escola é o ambiente mais apropriado para a realização de projetos de educação ambiental, evidencia-se a necessidade de desenvolvimento de projetos que promovam a sensibilização e a educação ambiental dos indivíduos em relação aos resíduos sólidos.

É imprescindível o desenvolvimento de ferramentas de sensibilização ambiental voltadas à exploração de assuntos ligados ao cotidiano dos alunos como, por exemplo, os resíduos sólidos, visando não apenas oferecer, no âmbito do 
processo ensino-aprendizagem, a assimilação de novos conhecimentos e o desenvolvimento das capacidades cognitivas dos alunos sobre temas ambientais, mas também estimular uma valorização dos aspectos ligados ao meio ambiente.

\subsection{REALIZAÇÃO DA PALESTRA}

As técnicas de sensibilização ambiental podem proporcionar a compreensão e transformação da realidade ambiental dos alunos (OLIVEIRA et al., 2013). Para tal, foi realizada uma palestra interativa com os alunos, sendo uma em cada turno (Figura 2).

Durante a palestra os alunos foram convidados a interagir com o palestrante. Alguns estudantes colocaram suas apiniões e seus conhecimentos prévios quando questionados sobre o tema que estava sendo apresentado, e também fizeram perguntas a fim de esclarecer suas dúvidas.

Após o término da palestra, alguns alunos que não se sentiram à vontade para esclarecer suas dúvidas, procuraram o palestrante para fazer mais algumas peguntas. A interação com os alunos a fim de esclarecer as suas dúvidas é imprescindível na realização de atividades de educação ambiental, pois a consciência ambiental requer indivíduos que possuam o conhecimento ambiental (SADIK; SADIK, 2014).

Figura 2: Fotografia da palestra realizada no teatro municipal de Areia Branca dos Assis.

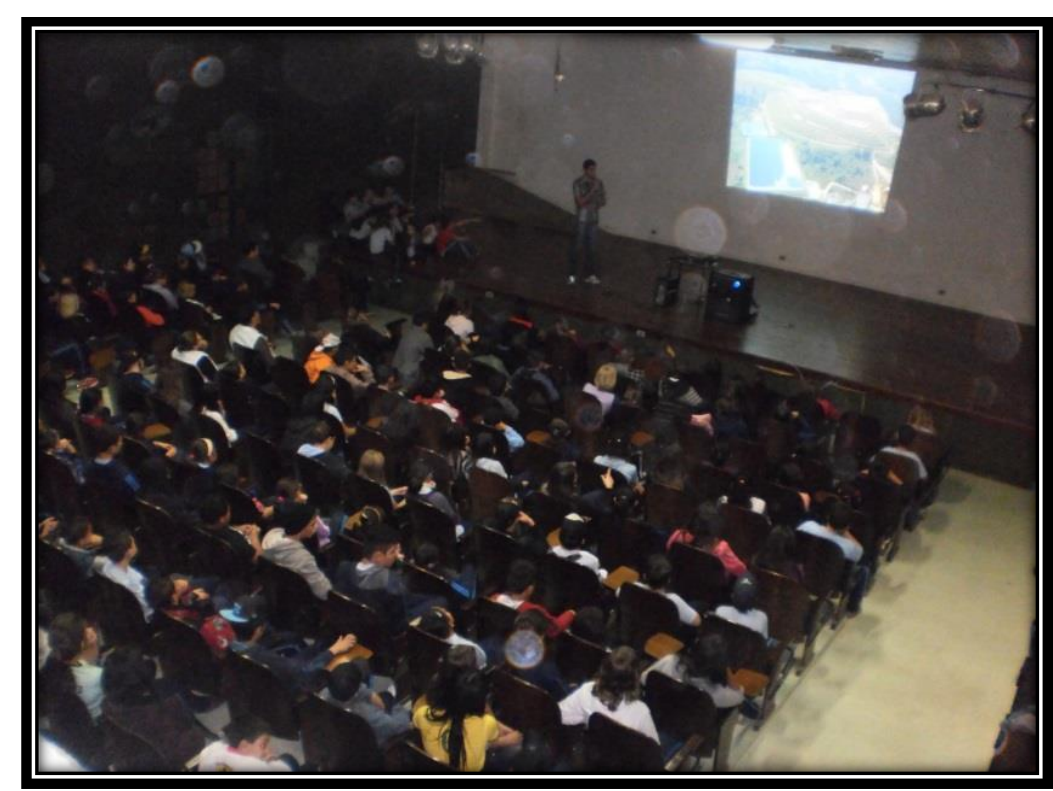

Fonte: Autoria própria (2014). 
Todo projeto de educação ambiental necessita da posterior avaliação (HEIMLICH, 2010). Após a realização da palestra, um novo questionário (Quadro 1) foi aplicado buscando verificar se os objetivos propostos foram atingidos (BASTOS; MACEDO; MOREIRA, 2005).

\section{Quadro 1: Questionário aplicado aos alunos após a realização da palestra.}

\begin{tabular}{|c|c|}
\hline $\begin{array}{l}1 \text { Sua família separa os resíduos sólidos em sua casa? } \\
\text { ( ) Sempre ( ) As vezes ( ) Não separa } \\
2 \text { Você sabe o que é coleta seletiva? } \\
\text { ( ) Não. } \\
\text { ( ) Sim. Explique: } \\
3 \text { Qual é o primeiro passo para diminuir os impactos } \\
\text { ambientais causados pelos resíduos sólidos? } \\
\text { ( )Não gerar. ( )Reduzir. ( )Reutilizar. ( )Reciclar. } \\
\text { ( )Tratar. ( )Dispor em aterros sanitários. }\end{array}$ & $\begin{array}{l}5 \text { Você sabe a diferença entre resíduo } \\
\text { reciclável e resíduo orgânico? } \\
\text { ( ) Não } \\
\text { ( ) Sim. Explique: } \\
6 \text { Você considera importante separar os } \\
\text { resíduos sólidos? } \\
\text { ( ) Sim. Por que? } \\
\text { ( ) Não. Por que? } \\
7 \text { Quais atitudes você se propõem a fazer } \\
\text { para diminuir a quantidade de resíduos } \\
\text { sólidos gerados em sua casa? }\end{array}$ \\
\hline
\end{tabular}

Fonte: Autoria própria (2014).

A partir da realização da palestra, o termo utilizado com os alunos passou a ser "resíduos sólidos", pois a diferença deste com o termo "lixo" foi explicada durante a palestra.

\subsection{AVALIAÇÃO DA PALESTRA}

Separação dos resíduos sólidos nas residências dos alunos

Como opções de respostas os alunos tinham as alternativas "sempre", "às vezes" e "não separa". Os alunos já haviam respondido a esta questão anteriormente à palestra, na etapa da formulação do diagnóstico da percepção ambiental dos alunos. Observa-se na Figura 3, que os resultados obtidos após a palestra foram menos satisfatórios que os obtidos anteriormente a ela. A porcentagem de famílias que sempre realiza a separação apresentou uma redução de $41,8 \%$ para $29,6 \%$, enquanto os alunos que relataram que suas famílias realizam a separação com alguma frequência, porém não sempre, aumentou de $48,6 \%$ para 
$55,6 \%$, e a porcentagem de famílias que não fazem a separação aumentou de $12,6 \%$ para $14,8 \%$.

Figura 3: Resultados obtidos com as respostas dos alunos antes e após a realização da palestra de sensibilização referentes a frequência da separação dos resíduos sólidos, $\mathbf{N}=\mathbf{2 0 0}$.

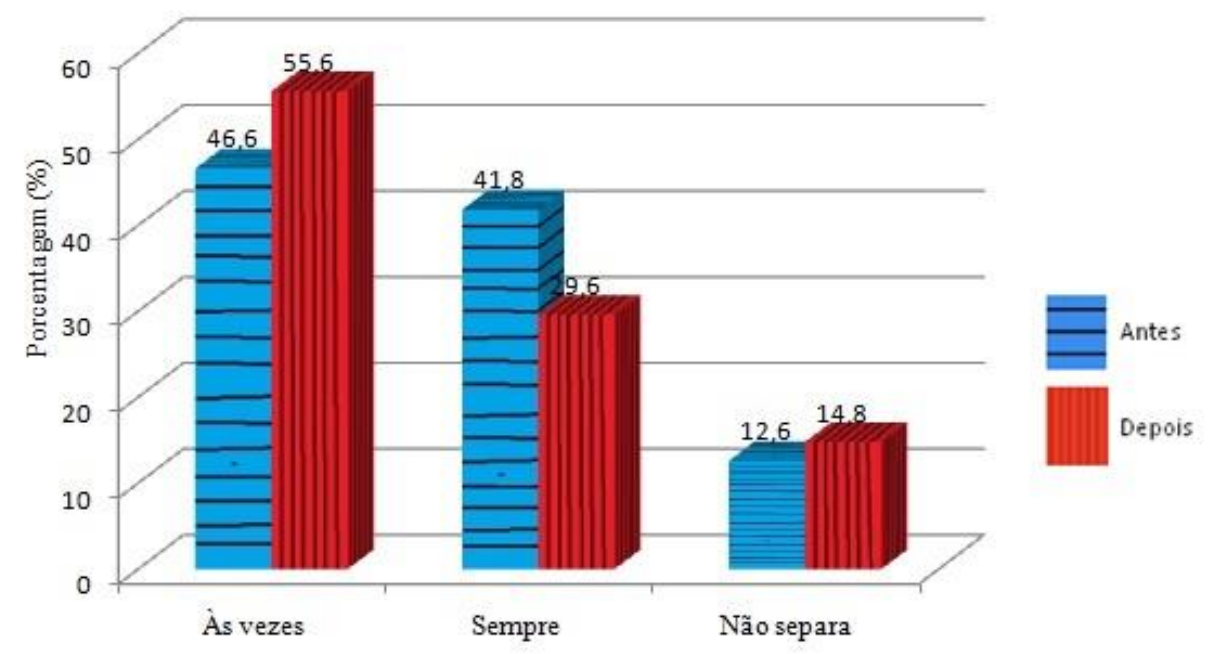

Frequência que as familias dos alunos realizam a separação dos resíduos

Fonte: Autoria própria (2014).

As mudanças não satisfatórias apresentadas pelos resultados da Figura 3 podem estar relacionadas a duas hipóteses. A primeira é que os alunos posteriormente a palestra sentiram-se mais sensibilizados (OLIVEIRA et al., 2013) quanto à problemática dos resíduos sólidos e compreenderam a necessidade de realizar a separação, sendo mais sinceros em suas respostas. Anteriormente a palestra, os alunos responderam a questão com poucos critérios, omitindo a veracidade dos dados.

A segunda hipótese é que os alunos tiveram mais conhecimento sobre a separação dos resíduos sólidos após a palestra e, perceberam que a forma como estavam realizando a separação não era a correta. Segundo essa hipótese, a educação ambiental abordou uma de suas finalidades, que é a construção do conhecimento voltada para a melhoria das questões ambientais (ESTEVES et al., 2011). 


\section{Conhecimento sobre coleta seletiva}

Os alunos dispunham de duas alternativas para suas respostas, "sabe" e "não sabe". Os alunos foram solicitados a desenvolverem um pequeno parágrafo justificando sua resposta. Após as análises dos dados, verificou-se que a maioria dos alunos, $64,7 \%$ soube descrever com clareza o conceito de coleta seletiva, contra $35,3 \%$ que não sabia ou não soube explicar.

A palestra pode ter proporcionado melhoras no conhecimento a respeito do assunto, o que pode contribuir para desencadear um repensar sobre as questões ambientais (MARCOMIN et al., 2013). Segundo Brasília (2001), a palestra transmite informações para favorecer a reflexão e o debate sobre o meio ambiente, contribuindo para uma postura cidadã crítica, podendo levar alguns indivíduos a atuarem de forma ambientalmente correta. Em estudo realizado por Vanelli (2011), visando analisar as percepções de alunos de uma escola referente aos resíduos sólidos, utilizando de palestras como ferramenta de sensibilização, a percepção dos alunos também melhorou após as atividades.

Porém, mesmo com o conhecimento adquirido pelos alunos, ainda é necessário que haja a mudança de atitudes por parte da população, contribuindo para a gestão adequada dos resíduos sólidos, e que o poder público também faça sua parte e forneça a infraestrutura adequada para que a população possa realizar a separação e os resíduos serem coletados e destinados corretamente.

\section{Técnicas de minimização apresentadas durante a palestra que podem} ser utilizadas para reduzir os impactos ambientais causados pelos resíduos sólidos

Os alunos poderiam optar por uma entre seis alternativas de respostas, como pode ser observado na Figura 4. As opções de respostas foram pensadas de forma a atender as técnicas de minimização estabelecidas pela Política Nacional de Resíduos Sólidos (não geração, redução, reutilização, reciclagem, tratamento e disposição final ambientalmente adequada dos rejeitos). A grande maioria dos alunos (51\%) optou pela não geração como primeiro passo para a minimização dos resíduos sólidos e para os impactos ambientais causados por eles. Da mesma maneira, a opção "dispor em aterros sanitários" foi a que apareceu em menor porcentagem $(3,7 \%)$ nos questionários respondidos pelos alunos. 
Notou-se um elevado índice de alunos que corresponderam às expectativas. Esses resultados alcançados (Figura 4) comprovam a aquisição, pelos alunos, de novos conhecimentos através da atividade de sensibilização ambiental utilizada. Para conseguir uma mudança para uma sociedade mais ecologicamente correta, é preciso preparar os alunos e a sociedade como um todo, com o conhecimento necessário, habilidades, ferramentas e experiências (WANG et al., 2013).

Figura 4: Técnicas de minimização de resíduos sólidos pela Política Nacional de Resíduos Sólidos apontadas pelos alunos, $\mathbf{N}=192$.

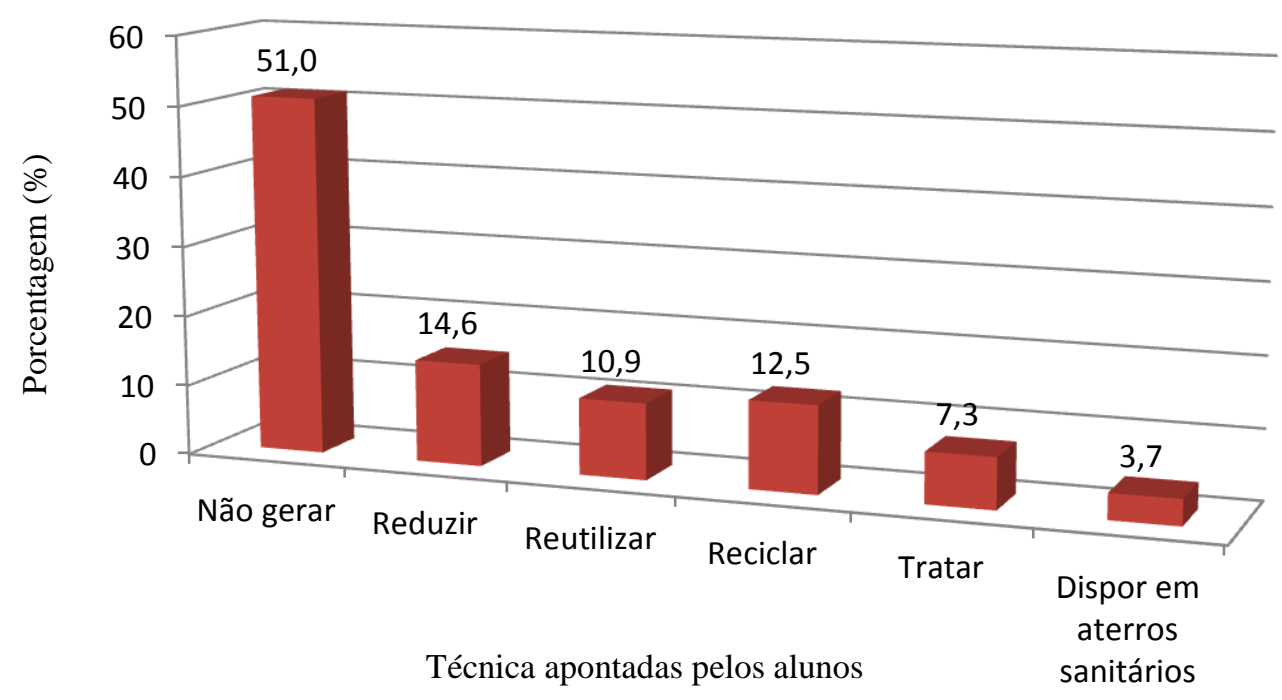

Fonte: Autoria própria (2014).

Com base nessas informações (Figura 4), as técnicas de sensibilização ambiental que envolvem esforços em trabalhar problemáticas atuais sobre os resíduos sólidos e sua complexidade contribuem para a inserção de conceitos importantes e necessários para a assimilação do assunto pelos alunos (SILVA, 2009).

\section{Conhecimento adquiridos com a palestra}

Perguntou-se o que os alunos aprenderam de mais importante na palestra. Apenas $1,06 \%$ dos alunos não responderam a esta questão. Os demais responderam, sendo que algumas expressões que denotam a compreensão sobre a importância de alguns temas foram ressaltadas pelos alunos, conforme se vê no Quadro 2. 
Quadro 2: Expressões dos alunos que demonstram a importância dos conhecimentos adquiridos durante a palestra.

"Que materiais simples de nosso cotidiano podem causar tanto impacto ambiental".

"Que devemos separar o lixo, pois são coisas que podemos reciclar ou reaproveitar, mas se misturar com os orgânicos não há como reaproveitar".

"Não gerar resíduos sólidos".

"Que devemos separar os resíduos sólidos para facilitar a reciclagem".

"Se não gerarmos lixo, vai diminuir muito nos aterros sanitários".

"Que o mais importante é não gerar lixo, para não poluir o meio ambiente".

"Que alguns resíduos sólidos demoram para se decompor, mais do que a minha vida inteira".

Fonte: Autoria própria (2014).

A função das técnicas de sensibilização, além de promover a conscientização dos indivíduos, é proporcionar a divulgação de informação, pois fornecem às pessoas conhecimentos sobre os problemas ambientais a serem enfrentados. Essas informações ajudam a amadurecer e enraizar os sentimentos despertados, momento quando se pensa e reflete sobre o que se sente, levando o aluno a compreender os problemas ambientais (SILVEIRA; AFONSO; ARRUDA, 2008).

Quando o indivíduo é capaz de identificar os problemas ambientais e suas causas no próprio ambiente onde está inserido, conforme observado nas expressões dos alunos no Quadro 2, ele pode estar sensibilizado ambientalmente, e também pode apontar as soluções para os problemas. Quando temas que fazem parte da vida dos indivíduos são abordados em técnicas de sensibilização ambiental, suas experiências e pensamentos são valorizados (BLANCHET-COHEN; REILLY, 2013), podendo levar o aluno a saber como atuar em diversas situações que ocorrem em seu cotidiano.

\section{Percepção sobre a diferença entre resíduo reciclável e resíduo} orgânico

Para suas respostas, os alunos puderam escolher entre duas opções, "sabe" e "não sabe". Os alunos foram solicitados a escrever um pequeno parágrafo justificando sua resposta. Esta mesma questão já havia feito parte do questionário aplicado anteriormente a palestra de sensibilização, na realização do diagnóstico da 
percepção ambiental alunos, momento em que apenas $46,6 \%$ dos alunos sabiam diferenciar resíduos recicláveis de resíduos orgânicos, conforme observado na Figura 5. Após a realização da palestra, a porcentagem de alunos que souberam explicar a diferença entre resíduos recicláveis e resíduos orgânicos aumentou para aproximadamente $65 \%$.

Novamente, nota-se a melhoria na percepção dos alunos, ressaltando a opinião de Janke et al. (2012), que apontam para a necessidade da educação ambiental produzir e divulgar conhecimento sobre o meio ambiente, afim de permitir e facilitar uma abordagem mais aprofundada. Logo, a participação de alunos em atividades relacionadas à preservação do meio ambiente deve ser incentivada (RUCHTER; KLAR; GEIGER, 2010).

Figura 5: Comparação entre a percepção dos alunos sobre resíduos recicláveis e resíduos orgânicos antes e após a realização da palestra de sensibilização, $\mathbf{N}=200$.

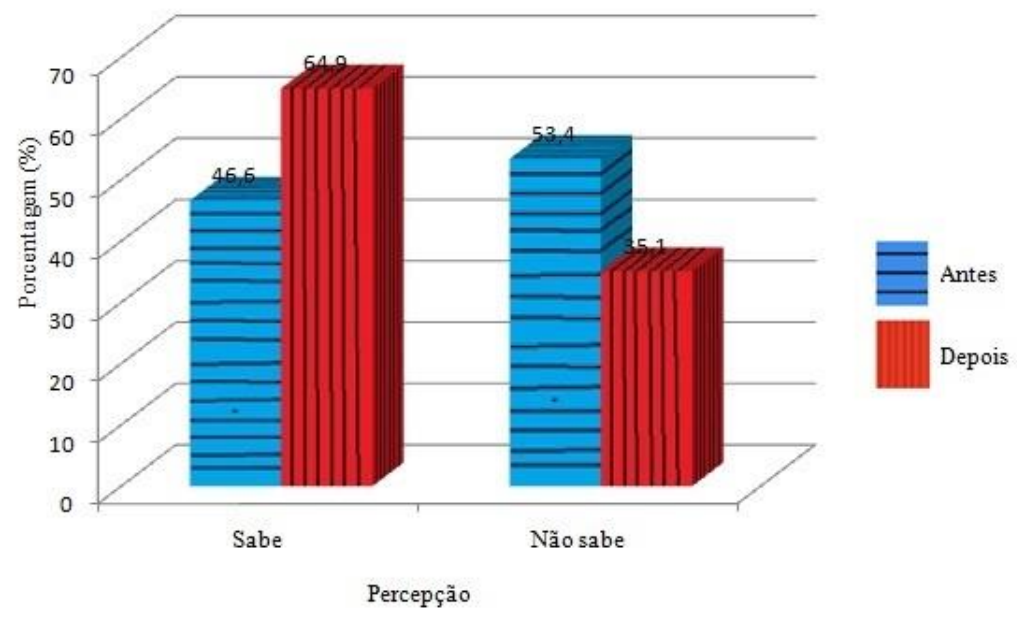

Fonte: Autoria própria (2014).

\section{Importância de separar os resíduos sólidos}

A palestra também abordou temas referentes à separação dos resíduos sólidos e os alunos poderiam escolher entre duas opções "sim" (considera importante) e "não" (não considera importante). Em qualquer uma das duas alternativas, os alunos eram solicitados a justificar suas respostas. Do total de alunos, 1,6\% respondeu não considerar importante a separação dos resíduos sólidos, porém não justificou suas respostas. Nos 98,4\% dos que responderam "sim" e justificaram suas respostas, puderam ser observadas em suas justificativas, várias 
expressões que denotam a compreensão sobre a importância de se fazer a separação como forma de minimização de resíduos sólidos e impactos ambientais, conforme se vê no Quadro 3.

Quadro 3: Algumas justificativas dos alunos sobre a importância de realizar a separação dos resíduos sólidos.

"Sim, para facilitar a reciclagem".

"Sim, porque se misturá-los não é mais reciclável".

"Para que eles não parem nos lixões ao ar livre".

"Para ser melhor administrado na hora de ser reciclado".

"Vai ajudar ainda mais o coletores/separadores de lixo".

"Sim, porque dá para reciclar e assim reduz os impactos ambientais."

"Porque assim a gente diminui a quantidade de lixo".

"É importante porque com pequenas atitudes podemos ajudar nosso planeta".

"Para que os resíduos sólidos não fiquem contaminados".

Fonte: Autoria própria (2014).

No Quadro 3 também é possível perceber que os alunos demonstram compreensão do conhecimento, pois apontam várias opiniões relevantes e favoráveis à reciclagem. O conhecimento ambiental é essencial para que os indivíduos coloquem em prática atitudes mais responsáveis (SADIK; SADIK, 2014).

A interação do aluno com os problemas ambientais enfrentados em seu cotidiano, pode proporcionar a percepção do meio ambiente de uma maneira diferente (DINIZ; VIVEIRO, 2009) e desta forma, identificar problemas que o afetam e suas causas. Quando isto ocorre, o indivíduo está um passo a frente em direção ao processo de conscientização.

\section{Ideias apontadas pelos alunos para diminuir a quantidade de resíduos} sólidos gerados em suas residências

Do total de alunos, apenas 5\% não respondeu a esta questão. Os demais descreveram ideias que podem realizar para promover a minimização dos resíduos sólidos e impactos ambientais causados por eles, resultando assim, em melhorais na qualidade ambiental na sua comunidade. Algumas dessas ideias consideradas mais relevantes foram separadas e apresentadas no Quadro 4. 
Quadro 4: Ideias propostas pelos alunos para minimizar a quantidade de resíduos sólidos produzidos em suas residências.

"Separando, reaproveitando os resíduos recicláveis".
"Separá-los dos orgânicos, evitar consumir alimentos com embalagens".
"Não gerar, o material não produzido não agride o meio ambiente".
"Separar o lixo seco, limpando-o e não gerar muito lixo".
"Reciclar o lixo da minha casa e orientar as outras pessoas".
"Comprar menos objetos que precisam de sacolas".
"Não gerar muitos resíduos para diminuir a quantidade".
"Continuar separando o lixo e ajudar cada vez mais o meio ambiente e orientar
as pessoas".
"Ao ir fazer compras levar a minha própria sacola".
"Separar com dois cestos de lixo, um de lixo orgânico e outro de resíduos
recicláveis". Fonte: Autoria própria (2014).

Nota-se a partir do Quadro 4 que os alunos, em suas expressões, demonstram uma preocupação com a questão dos resíduos sólidos e até são capazes de apontar algumas ideias para a redução dos impactos ambientais e para a minimização dos resíduos sólidos. Conforme ressaltado por Silva (2009, p. 189), "o envolvimento dos alunos nas atividades, e a melhoria da qualidade do ambiente, constituem-se em resultados positivos alcançados por meio dos projetos de educação ambiental”.

A avaliação de um projeto de educação ambiental envolve mais do que a expressão de conhecimentos sobre o meio ambiente. Ela deve envolver resultados de ações e mudanças dos sujeitos diretamente envolvidos com o espaço de sua atuação. A educação ambiental não tem uma relação direta com uma atividade ou com um estudo sobre um tema, mas com os desdobramentos que ocorrem e as intervenções dos sujeitos na complexidade do contexto socioambiental (SPAZZIANI; SILVA, 2009). Por exemplo, não é importante que um indivíduo tenha conhecimento sobre a conservação da água, é importante que a água seja conservada em toda a comunidade através das contribuições do indivíduo (HEIMLICH, 2010).

Nessa pesquisa foi possível observar que os alunos, mesmo apresentando pouca experiência de vida, estão aptos à inserção de temas de grande importância, como o caso da minimização de resíduos sólidos. A educação ambiental nas escolas é uma ferramenta essencial para a formação de estudantes e indivíduos mais conscientes (TSAI, 2012), e o trabalho com alunos de nível fundamental e 
médio se mostrou eficaz, pois é nessa faixa etária que esses indivíduos estão mais suscetíveis às mudanças. Dessa forma, segundo Oliveira et al. (2013, p. 35), "a inserção de valores ambientais nesta etapa da vida dos indivíduos poderá promover uma mudança comportamental no modo de agir e pensar. Isso, em longo prazo, pode contribuir para uma mudança cultural e social na sociedade".

\section{CONCLUSÕES}

Baseado no estudo das percepções ambientais de alunos do colégio estadual, percebe-se que os estudantes investigados apresentaram, de uma forma geral, previamente às atividades de sensibilização, uma percepção ambiental incipiente. A maioria dos alunos não soube explicar o conceito de resíduos sólidos e a diferença entre resíduos recicláveis e resíduos orgânicos.

A partir da palestra de sensibilização realizada com os alunos e da análise dos resultados dos questionários aplicados aos alunos após as palestras, observouse uma evolução na percepção dos alunos em relação a alguns aspectos desenvolvidos na atividade de sensibilização ambiental. Os alunos foram capazes de construir e descrever suas concepções sobre coleta seletiva; identificaram as técnicas de minimização de resíduos sólidos mais adequadas ambientalmente; compreenderam a importância da separação dos resíduos. Além disso, aumentou o número de alunos que soube descrever a diferença entre resíduos recicláveis e resíduos orgânicos; os alunos apresentaram novos conhecimentos adquiridos; e apresentaram ideias pertinentes para reduzir a quantidade de resíduos sólidos gerados em suas residências.

Do mesmo modo, foi possível identificar a importância da escola como ambiente propício a inserção de ferramentas de sensibilização ambiental. Porém, também se constatou que no Projeto Político Pedagógico (PPP) da escola, não existe nenhuma orientação aos professores sobre educação ambiental. Desta maneira, é necessário fazer uma reformulação no PPP do colégio, inserindo as diretrizes estabelecidas pela Política Estadual de Educação Ambiental (Lei 17505/2013) e/ou pelos Parâmetros Curriculares Nacionais referentes à educação ambiental, para que ela seja abordada em suas várias temáticas, incluindo nelas os resíduos sólidos. 


\section{REFERÊNCIAS}

ABRELPE. Associação Brasileira de Empresas de Limpeza Pública e Resíduos Especiais. Panorama dos Resíduos Sólidos no Brasil, 2013. Disponível em: http://www.abrelpe.org.br/. Acesso em: 06/08/2014.

BASTOS, F. F.; MACEDO, N. S. S.; MOREIRA, N. M. C. P. A educação ambiental no curso normal superior do Instituto Superior de Educação de Santo Antonio de Pádua: um estudo de caso. 2005. 51 f. Monografia - Fundação de Apoio à Escola Técnica, Santo Antônio de Pádua, 2005.

BATOOL, S. A.; NAWAZ, M. Municipal solid waste management in Lahore City District, Pakistan. Waste Management, v. 29, 1971-1981. 2009.

BLANCHET-COHEN, N. REILLY, R. C. Teachers' perspectives on environmental education in multicultural contexts: Towards culturally-responsive environmental education. Teaching and Teacher Education. 36. 12-22. 2013.

BOER, E.; DRCZAK, A. J.; KOWALSKI, Z.; KULCZYCKA, J.; SZPADT, R. A review of municipal solid waste composition and quantities in Poland. Waste Management, v. 30, 369-377. 2010.

BRASIL. Política Nacional de Resíduos Sólidos. 2010. Disponível em: http://www.camara.gov.br/sileg/integras/501911.pdf. Acesso em: 11/04/2012.

BRASÍLIA. Secretaria de Educação Fundamental - MEC. Ciclo de palestras sobre meio ambiente. Brasília: SEF, 2001.

CAMPOS, M. C. C.; NETO, N. M. S. M.; VERAS, E. S.; SOUZA, Z. G. E. F. Percepção ambiental: experiência em escolas de ensino fundamental em Humaitá (AM). Ambiência Guarapuava (PR), v.8 n.1 p.35-46, ISSN $1808-0251.2012$.

CHATTOPADHYAY, S.; DUTTA, A.; RAY, S. Municipal solid waste management in Kolkata, India - A review. Waste Management, v. 29, 1449-1458. 2009.

CRISOSTIMO, A. L. Educação ambiental, reciclagem de resíduos sólidos e responsabilidade social: formação de educadores ambientais. Rev. Conexão UEPG, v. 2, 88-95, 2011.

DAMINELLI, R. M.; SILVA, S. M. Casos de Sucesso na Educação Ambiental. Curitiba: IESDE, 2009.

DINIZ, R. E. S.; VIVEIRO, A. A. Atividades de campo no ensino ciencias e na educação ambiental: refletindo sobre as potencialidades desta estratégia na prática escolar. Rev. Ciência em Tela. Vol. 2, № 1.2009.

ESTEVES, R. C.; SILVA, A. B. C. G.; ROZA, F. C.; GONÇALVES, L. P.; FREITAS, L. S.; PAULA, T. P. Como aplicar educação ambiental no dia a dia de uma escola pública. Rev. Comunicação e Educação Ambiental. Volume 1 - No 1- Janeiro/Junho de 2011.

HEIMLICH, J. E. Environmental education evaluation: Reinterpreting education as a strategy for meeting mission. Evaluation and Program Planning v.33.180-185. 2010.

HELAL, M. P.; FELIX, C. C. A. Implantação de coleta seletiva em um condomínio de casas na Barra da Tijuca. Rev. Comunicação e Educação Ambiental. Volume 1 - No 1- Janeiro/Junho de 2011.

IBGE. Instituto Brasileiro de Geografia e Estatística. Censo Demográfico 2010. Disponível em: http://www.ibge.gov.br/home/estatistica/populacao/censo2010/primeiros resultados/default primeiros resultados.shtm. Acesso em: 10/04/2012. 
IBGE. Instituto Brasileiro de Geografia e Estatística. Atlas de saneamento 2011. Rio de Janeiro, 2011.

IPARDES. Instituto Paranaense de Desenvolvimento Econômico e Social, Perfil dos Municípios. Disponível

em: http://www.ipardes.gov.br/perfil municipal/MontaPerfil.php?Municipio=83800\&btOk=0k. Acesso em: 04/07/2012.

JANKE, N.; TOZONI REIS, M. F. C.; TALAMONI, J. L. B.; RUIZ, S. S.; NEVE, J. P.; TEIXEIRA, L. A.; CASSINI, L. F.; FESTOZO, M. B.; MAIA, J. S. S.; SANTOS, H. M. S.; CRUZ, L. G.; MUNHOZ, R. H. A educação ambiental na escola básica: diretrizes para a divulgação dos conhecimentos científicos. Pesquisa em Educação Ambiental, vol. 7, n. 1 - pp. 29-48, 2012.

LAYRARGUES, P. P. Muito além da natureza: educação ambiental e reprodução social. In: LOUREIRO, C.F.B. et al. (Orgs.) Pensamento complexo, dialética e educação ambiental. São Paulo: Cortez. p. 72-103. 2006.

MARCOMIN, F. E.; PEREIRA, C.C.; SILVA, F. K.; RICKEN, I. Percepção e sensibilização ambiental como instrumentos à educação ambiental. Rev. Eletrônica Mestr. Educ. Ambient. E-ISSN 15171256, v. 30, n.2, p. 86 - 106, jul./dez. 2013.

MATTEI, G.; ESCOSTEGUY, P. A. V. Composição gravimétrica de resíduos sólidos aterrados. Eng. Sanit. Ambient. v.12 no.3 Rio de Janeiro July/Sept. 2007.

MOGHADAM, A. M. R.; MOKHTARANI, N.; MOKHTARANI, B. Municipal solid waste management in Rasht City, Iran. Waste Management, v. 29, 485-489. 2009.

MORAES, M. S.; SIQUEIRA, M. M. Saúde coletiva, resíduos sólidos urbanos e os catadores de lixo. Ciênc. saúde coletiva v.14 no. 6 Rio de Janeiro. Dec. 2009.

OLIVEIRA, E. M.; SANTOS, W. M. B.; MORAIS, J. L.; BASSETTI, F. J.; BERGAMASCO, R. Percepção ambiental e sensibilização de alunos de colégio estadual sobre a preservação da nascente de um rio. Rev. Eletrônica Mestr. Educ. Ambiental. ISSN 1517-1256, v. 30, n. 1, p. 23 37, jan./ jun. 2013.

ONOFRE, F. L. Estimativa da geração de resíduossólidos domiciliares. 2011. 100 f. Dissertação (Mestrado em Engenharia Urbana e Ambiental) - Universidade Federal da Paraíba. João Pessoa. 2011.

PEDROSO, K.; CERUTI, F. C. Programa de gerenciamento de resíduos sólidos urbanos: uma proposta para pequenos municípios brasileiros. VII Semana de Engenharia Ambiental. UNICENTRO, Campus Irati. Junho de 2009.

PREFEITURA MUNICIPAL DE SÃO JOSÉ DOS PINHAIS. Mapa de localização do município. Acesso em: 13/08/2014. Disponível em: http://www.sjp.pr.gov.br/localizacao/.

RODRIGUES, J. H. O uso da mídia como estímulo à preservação ambiental no bairro alto. 2010 . 59 f. Monografia (Especialização em Educação Ambiental Urbana) - Escola Superior Aberta do Brasil, Vila Velha, 2010.

RUCHTER, M.; KLAR, B.; GEIGER, W. Comparing the effects of mobile computers and raditional approaches in environmental education. Computers \& Education. 54. 1054-1067. 2010. 
SADIK, F. SADIK, S. A study on environmental knowledge and attitudes of teacher. Procedia - Social and Behavioral Sciences. 116. 2379 - 2385. 2014.

SANTOS, E. T. A. Educação ambiental na escola: conscientização da necessidade de proteção da camada de ozônio. 2007. 53 f. Monografia (Especialização em Educação Ambiental) Universidade Federal de Santa Maria, Santa Maria, 2007.

SILVA, A. P. Educação ambiental em resíduos sólidos nas unidades escolares de Presidente Prudente - SP. 2009. 207 f. Dissertação (Mestrado em Geografia) - Universidade Estadual Paulista, Presidente Prudente, 2009.

SILVA, N. K. T.; SILVA, S. M. Educação Ambiental e Cidadania. Curitiba: IESDE, 2009.

SILVEIRA, G. T. R.; AFONSO, C. G.; ARRUDA, L. N. Resíduos sólidos e educação ambiental para a comunidade do Instituto de Ciências Biológicas e da Saúde da PUC Minas: uma oportunidade de reflexão sobre o discurso teórico e a prática ambiental no mundo acadêmico. Rev. eletrônica Mestr. Educ. Ambient. ISSN 1517-1256, v. 21, julho a dezembro de 2008.

SOARES, L. G. C.; SALGUEIRO, A. A.; GAZINEU, M. H. P. Educação ambiental aplicada aos resíduos sólidos na cidade de Olinda, Pernambuco - um estudo de caso. Revista Ciências \& Tecnologia, ano 1, n. 1, julho-dezembro 20072007.

SPAZZIANI, M. L.; SILVA, P. G. F. Planejamento e Avaliação em Projetos de Educação Ambiental. Curitiba: IESDE, 2009.

TOZONI-REIS, M. F. C. Metodologias Aplicadas à Educação Ambiental. 2. ed. Curitiba: IESDE, 2008.

TSAI, W. T. An investigation of Taiwan's education regulations and policies for pursuing environmental sustainability. International Journal of Educational Development v.32. 359-365. 2012.

VANELLI, J. Percepção ambiental da coleta seletiva no colégio municipal e estadual em um município de pequeno porte da Região Oeste do Paraná. 2011. 38 f. Trabalho de Conclusão de Curso (Graduação) - Curso Superior de Tecnologia em Gestão Ambiental. Universidade Tecnológica Federal do Paraná, Medianeira, 2011.

WANG, Y.; SHI, H.; SUN, M.; HUISINGH, D.; HANSSON, L.; WANG, R. Moving towards an ecologically sound society? Starting from Green universities and environmental higher education. Journal of Cleaner Production. 61, 1-5. 2013.

ZHANG, D.; KEAT, T. S.; GERSBERG, R. M.A comparison of municipal solid waste management in Berlin and Singapore.Waste Management, v.30. 921-933. 2010. 